\title{
Molecular correlates of cortical network modulation by long-term sensory experience in the adult rat barrel cortex
}

\author{
Astrid Vallès, ${ }^{1,2}$ Ivica Granic, ${ }^{1,2}$ Peter De Weerd, ${ }^{1,2,3}$ and Gerard J.M. Martens ${ }^{2,3,4}$ \\ ${ }^{1}$ Department of Neurocognition, Faculty of Psychology and Neuroscience, Maastricht University, 6229 EV Maastricht, The \\ Netherlands; ${ }^{2}$ Department of Molecular Animal Physiology, Radboud University, Donders Institute for Brain, Cognition and Behaviour \\ (Centre for Neuroscience), Nijmegen Centre for Molecular Life Sciences, 6525 GA Nijmegen, The Netherlands
}

\begin{abstract}
Modulation of cortical network connectivity is crucial for an adaptive response to experience. In the rat barrel cortex, longterm sensory stimulation induces cortical network modifications and neuronal response changes of which the molecular basis is unknown. Here, we show that long-term somatosensory stimulation by enriched environment up-regulates cortical expression of neuropeptide mRNAs and down-regulates immediate-early gene (IEG) mRNAs specifically in the barrel cortex, and not in other brain regions. The present data suggest a central role of neuropeptides in the fine-tuning of sensory cortical circuits by long-term experience.
\end{abstract}

[Supplemental material is available for this article.]

The storage and retrieval of information in and from the cerebral cortex is crucial for cognition. To permit effective adaptive responses, cortical networks must remain plastic throughout life, and their functional organization needs to be accurately adjusted depending on experience (Barnes and Finnerty 2010). The functional and morphological changes in cortical connectivity following sensory experience have been well established, especially in the rodent visual and somatosensory (barrel) cortices (Fox and Wong 2005). At the level of the barrel cortex, these alterations have been observed following various sensory manipulations (Feldman and Brecht 2005). One of the most striking changes takes place when animals are reared in an enriched environment (EE), after which reduced cortical whisker representations, suppressed evoked neuronal responses, as well as smaller and betterdefined receptive fields are observed (Polley et al. 2004). Similar effects occur upon single-whisker experience. When all but one whisker is clipped on one side of the snout, that whisker's functional representation contracts if the animal is allowed to explore the environment (Polley et al. 1999). Similarly, contracted whisker functional representations are also observed after single-whisker stimulation (Welker et al. 1992), which is accompanied by an increase in inhibitory synapses (Knott et al. 2002). Therefore, increased whisker use leads to cortical whisker receptive fields that are spatially focused and more metabolically efficient (Frostig 2006), which at a population level can translate into weaker overall excitability (Polley et al. 2004). The increased specificity of whisker representations is critically dependent on experience, as the spared whisker representation shows expansion rather than contraction in animals housed under standard conditions (i.e., with limited whisker use). Although the exact behavioral consequences of experience-induced refinement of whisker representations caused by EE are not known, this refinement may reduce the

\footnotetext{
${ }^{3}$ These authors contributed equally to this work.

${ }^{4}$ Corresponding author

E-mail g.martens@ncmls.ru.nl

Article is online at http://www.learnmem.org/cgi/doi/10.1101/lm.034827.114.
}

signal-to-noise ratio, improve cortical information processing, and thereby enhance discriminative performance.

At the molecular level, the mechanisms steering this functional refinement are poorly understood. We have previously described the global changes in gene expression in the barrel cortex after a short period of EE. Compared to controls, EE leads to the differential expression of genes encoding transcription factors, including nuclear receptors, as well as of genes involved in the regulation of synaptic plasticity, cell differentiation, metabolism, and blood vessel morphogenesis (Vallès et al. 2011). However, genome-wide information on the molecular changes observed in the primary somatosensory cortex after long-term EE is lacking. This knowledge is crucial to understand the mechanisms underlying the functional and structural changes induced by long-term experience. Given the reported increase in inhibitory synapse number (Knott et al. 2002) after continuous whisker stimulation, we hypothesized that the contracted cortical receptive fields observed upon increased whisker use may be, at least partially, due to an increased signaling from interneurons.

To test this hypothesis, and to understand the molecular basis of the functional and morphological changes of EE rearing, in experiment 1 we performed mRNA expression profiling (microarray analysis) of the barrel cortex of adult Long-Evans rats placed in an EE environment for $28 \mathrm{~d}$ (large cage with enrichment, $n=8$ animals/cage). As a control, we used animals kept in their home cage (home-caged controls, HCC) for $28 \mathrm{~d}$ (standard cage, $n=2$ animals/cage) (see Supplemental Methods for details).

The 28-d period of sensory enrichment induced, in the rat barrel cortex, significant changes ( $\geq 1.3$ fold, $P<0.05$, SAM analysis) in the expression of only a limited number of genes, namely 29

(C) 2014 Vallès et al. This article is distributed exclusively by Cold Spring Harbor Laboratory Press for the first 12 months after the full-issue publication date (see http://learnmem.cshlp.org/site/misc/terms.xhtml). After 12 months, it is available under a Creative Commons License (AttributionNonCommercial 4.0 International), as described at http://creativecommons. org/licenses/by-nc/4.0/. 
of the $\sim 22,000$ genes present on the array (Fig. 1). Gene ontology (GO) enrichment analysis included significant enrichment of the GO categories neuropeptide signaling, synaptic transmission, and regulation of synaptic plasticity and transmission (Supplemental Table 1). The 13 genes (out of the 29 regulated genes) selected for qPCR analysis were all validated ( $t$-test, $P<0.05$ ) (Fig. $2 \mathrm{~A}, \mathrm{~B}$ ), confirming the results of the microarray analysis. Remarkably, a large portion (44\%) of the transcripts up-regulated in the EE group consisted of neuropeptide mRNAs. These included transcripts encoding cortistatin (Cort), cocaine- and amphetamine-regulated transcript (Cart), corticotrophin-releasing hormone (Crh) and its binding protein Crhbp, adenylate cyclase activating polypeptide 1 (Adcyap1, also known as Pacap), neuropeptide Y (Npy), and prepronociceptin (Pnoc). The remaining up-regulated genes code for transporters (such as the vesicular glutamate transporter 2, VGlut2), enzymes (such as phosphodiesterase 7A, Pde7a, and lysyl oxidase, Lox), or are involved in oxygen binding, among others (Fig. 1).
The up-regulation of neuropeptide mRNAs was accompanied by a striking down-regulation of a number of immediate-early genes (IEGs) (54\% of the down-regulated genes) (Fig. 1; Supplemental Table 1). Several of these are known to be involved in regulating synaptic plasticity and transcription, including the IEGs encoding activity-regulated cytoskeleton-associated protein (Arc), early growth response 1 (Egr1, also known as Zif268), FBJ osteosarcoma oncogene (Fos), immediate early response 5 (Ier5), and ring finger protein 39 ( $R f p 39$, also named Lirf). The clock genes period homolog 1 and 2 (Per1, Per2) and basic helix-loop-helix domain containing, class B2 and B3 (Bhlhb2, Bhlhb3), were also down-regulated, as was the gene coding for the type 4 muscarinic receptor (Chrm4), among others (Fig. 1).

To assess the specificity of these changes in terms of (1) somatosensory enrichment and (2) brain region, experiment 2 was performed, in which the enrichment procedure was similar to experiment 1 (EE group, large cage with enrichment, $n=8$ animals/cage), but in which, as a control group, animals placed in a large cage without enrichment (large cage control group, LCC, $n=8$ animals/ cage) were used (instead of $n=2$ animals/cage in standard cages as in experiment 1). Expression of the top three up- and top three down-regulated genes from the microarray results from the previous experiment was measured by qPCR in experiment 2. This was done not only in the barrel cortex but also in primary motor (M1) and visual (V1) cortex, striatum, and ventral posteromedial thalamic nucleus (VPM). In the barrel cortex, the top three up-regulated genes from the first experiment (neuropeptides Cart, Cort, and $\mathrm{Crh}$ ) were, although to a lesser extent, also significantly up-regulated in EE animals in comparison to LCC rats ( $t$-test, $P<0.05$ ) (Fig. 2C). However, none of the top three down-regulated genes from the first experiment (IEGs Arc, Egr1, and Per2) were significantly regulated in EE vs. LCC animals (Fig. 2C). In the two other cortical areas studied (M1 and V1), only the mRNA of the neuropeptide Cort was differentially expressed (up-regulated) in M1 from EE vs. LCC groups ( $t$-test, $P<0.05$ ), while the rest of the measured genes showed no significant differences (Fig. 2C). In the two additional noncortical regions analyzed (striatum and VPM) none of the measured genes showed significant differences between the EE and LCC groups (data not shown).

The two experiments showed important parallels and some differences. Importantly, our finding in experiment 1 that neuropeptides are up-regulated in primary somatosensory (barrel) cortex due to prolonged somatosensory experience was validated in experiment 2. However, although up-regulation of neuropeptides in both experiments was significant, the effects appeared smaller in experiment 2 (Fig. 2, A vs. C). To test the difference between experiments, we computed for the two experiments the
Figure 1. Long-term sensory enrichment induces significant changes in gene expression. Microarray analysis revealed differentially expressed genes in the rat barrel cortex following $28 \mathrm{~d}$ of enriched environment (EE) rearing (large cage with enrichment, $n=8$ animals/cage), in comparison to home-caged controls (HCC) (standard cage, $n=2$ animals/cage). Gene names, abbreviations, fold changes, and color-coded gene ontologies for up-regulated (top panel) and down-regulated (bottom panel) genes are indicated, together with the accession number of each gene. 

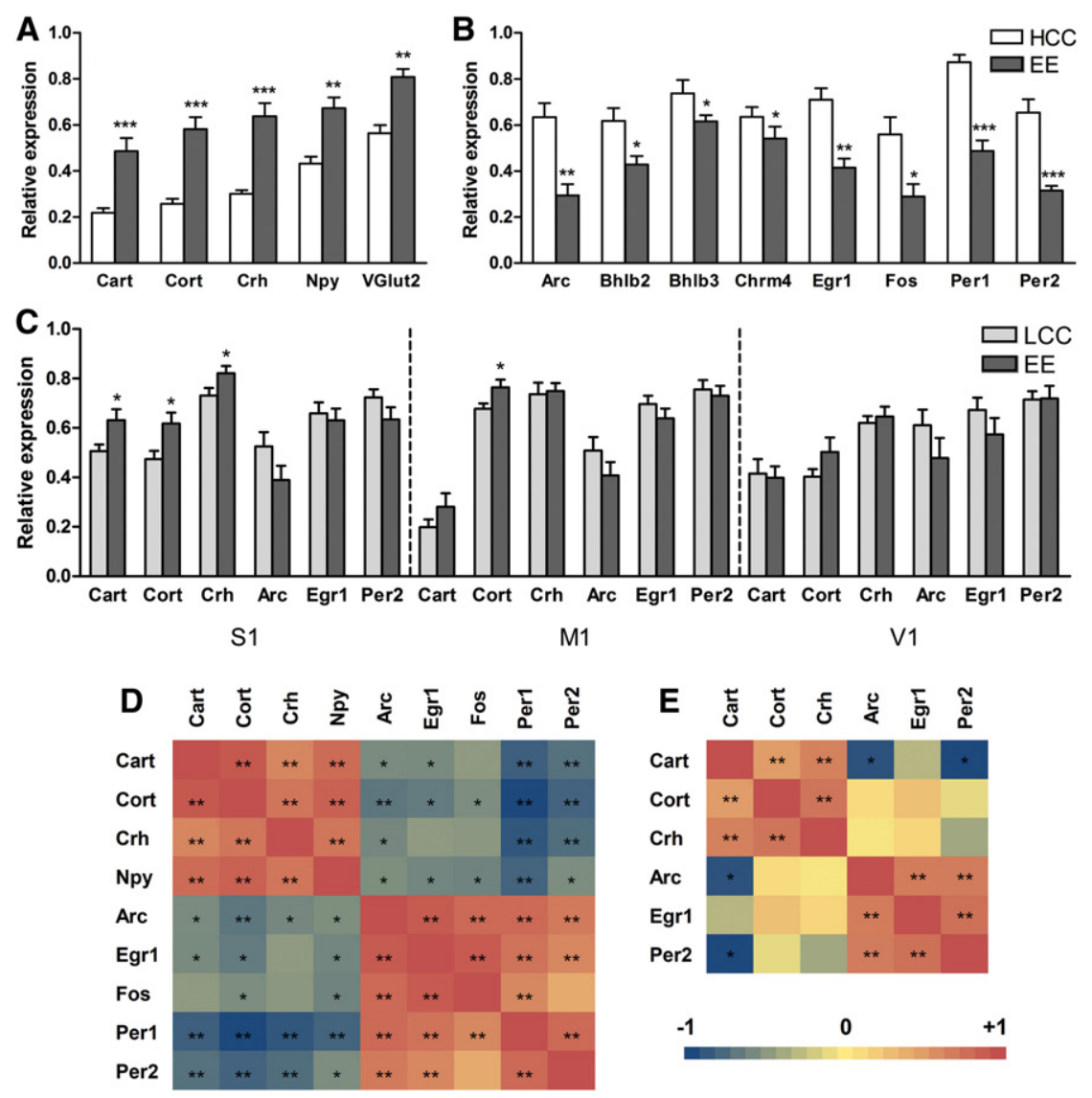

Figure 2. qPCR analysis of gene expression in different cortical regions after $28 \mathrm{~d}$ of enriched environment (EE). Normalized expression values of selected up-regulated $(A)$ and down-regulated $(B)$ genes in the barrel cortex after $28 \mathrm{~d}$ of $\mathrm{EE}$ (enrichment in large cage, $n=8$ animals/cage), in comparison to home-caged controls (HCC) (housed in standard cages, $n=2$ animals/cage) (experiment 1). (C) In experiment 2, expression of the top three up-regulated and down-regulated genes was measured in the barrel cortex (S1) and primary motor (M1) and visual (V1) cortices after $28 \mathrm{~d}$ of EE in comparison to control animals housed ( $n=8 /$ cage) in large cages (LCC group). For normalization, $\beta$-actin or $Y w h a z$ was selected as the housekeeping gene (most stable gene chosen). Bars represent average normalized expression values \pm SEM ( $n=8$ animals/group). Asterisks represent significant differences between home-caged control (HCC) and EE groups or large cage control (LCC) and EE groups (Student's $t$-test; $\left.\left.\left.\left[{ }^{*}\right] P<0.05,{ }^{* *}\right] P<0.01,{ }^{* * *}\right] P<0.001\right)$. A graphical view of Pearson correlations after multiple testing correction between all measured mRNA levels in the barrel cortex in the HCC vs. EE comparison $(D)$ and LCC vs. EE comparison $(E)$ is shown. The correlations are color-coded as indicated in the bar at the bottom left (from -1 to +1 ), and statistically significant correlations are tagged with asterisks (Pearson correlation, $\left[^{*}\right]$ corrected $P<0.05,[* *]$ corrected $P<0.01$ ).

expression level for each gene in each individual animal as a percentage of the control expression level averaged over all animals. These percentages were log-transformed (to homogenize variance) and entered in a repeated measures ANOVA with the withinsubject factor gene (3) and the between-subjects factor experiment (2). This analysis showed a main effect of experiment $\left(F_{(1,26)}=\right.$ 43.995, $P<0.001)$ in line with a greater neuropeptide up-regulation in experiment 1 than in 2 , no main effect of gene $\left(F_{(2,52)}=\right.$ $1.713, P=0.190)$, and no significant interaction $\left(F_{(2,52)}=0.171\right.$, $P=0.843)$. This result suggests that the smaller neuropeptide up-regulation in experiment 2 is more specifically linked to sensory than to social enrichment, because the social factors in experimental and control groups were better matched in experiment 2 (8 animals in EE and LCC groups) than in experiment 1 (8 animals in EE group, pairs of animals in HCC group). Conversely, the larger effect in experiment 1 may be seen as reflecting the addition of a social aspect to the enrichment as compared to experiment 2 . The sensory interpretation of experiment 2 is supported by the finding that the neuropeptide effects were overall quite specific for the barrel cortex (Fig. 2C). With respect to the IEGs, the results of the two experiments differ. We found no significantly reduced mRNA levels for the IEGs in experiment 2 , and a repeated measures ANOVA, as described above, showed a significantly larger down-regulation of IEGs in experiment 1 than in experiment 2 $\left(F_{(1,24)}=9.804, P=0.005\right)$ and a significant effect of gene $\left(F_{(2,48)}=19.071, P<\right.$ $0.001)$, but no significant interaction $\left(F_{(2,48)}=2.131, P=0.130\right)$. These findings may again reflect the higher similarity between control and EE groups in experiment 2 than in experiment 1 .

To further explore the relationship between neuropeptide and IEG levels, we performed correlation analyses among mRNA levels of all the measured genes in the barrel cortex, in both experiment 1 (HCC vs. EE comparison) and experiment 2 (LCC vs. EE comparison). As expected, mRNA levels of most of the analyzed neuropeptides positively correlated among themselves, and similarly also the levels of the majority of IEG mRNAs showed positive correlations among themselves (Pearson correlation, corrected $P<0.05$ ) (Fig. 2D,E). Interestingly, mRNA levels of neuropeptide and IEGs displayed negative correlations for many of the analyzed genes (Pearson correlation, corrected $P<0.05$ ), thus identifying two clusters of genes with opposite responses to EE. This clustering was pronounced in experiment 1 (HCC vs. EE comparison) (Fig. 2D), but less clear in experiment 2 (LCC vs. EE comparison) (Fig. 2E).

The genome-wide approach used thus revealed new insights into the mRNA changes underlying the neurophysiological effects of long-term somatosensory enrichment in the barrel cortex. The genomic changes induced by long-term EE were limited to a small number of genes, and specific to the barrel cortex. Strikingly, nearly half of the genes up-regulated following $28 \mathrm{~d}$ of EE were related to neuropeptide signaling, whereas the majority of the downregulated genes represented IEGs. At the cortical level, neuropeptides are primarily expressed in interneurons, which play crucial roles in neuronal sensory transmission (Markram et al. 2004; Fries 2005) and in the specificity of sensory neurons (Sillito 1975). Therefore, an increased tone of neuropeptide signaling may well play an important role in the functional refinement of the cortical network and enhanced specificity of neural responses in a variety of stimulation and learning conditions. The overall reduction of excitability reported by Polley et al. (2004) after longterm EE fits with these ideas.

How specific interneuron types act on cortical network depends on their molecular signature (expression of neuropeptides and calcium-binding proteins), their morphology and (electro)physiological features, as well as their cortical location/distribution (connectivity). Our hypothesis that increased neuropeptide 
signaling in interneurons may contribute to altered cortical network activity after long-term sensory experience is strongly supported by the cortical distributions of the neuropeptides upregulated in our study (Fig. 3), and their known functions in other brain systems (de Lecea et al. 1997; Yan et al. 1998a,b; Hannibal 2002; Markram et al. 2004; Karagiannis et al. 2009). For example, $\mathrm{Crh}$, up-regulated here together with its binding protein $\mathrm{Crhbp}$, depresses evoked excitatory responses in the rat sensorimotor cortex (Froc and Christie 2005). This is consistent with the reduced evoked responses found in the somatosensory cortex following EE rearing (Polley et al. 2004), although excitatory effects of Crh in the cortex have also been reported (Gallopin et al. 2006). Similarly, Cort and Npy, which were up-regulated in our study, decrease excitability in cortical circuits (Spier and De Lecea 2000; Bacci et al. 2002). Among the other up-regulated neuropeptides, Pnoc modulates glutamatergic functions (Kuzmin et al. 2009), and Adcyap1 modulates evoked responses in the hippocampus in a dose-dependent manner (Roberto et al. 2001), although excitatory effects of Adcyap 1 have also been described (Hu et al. 2011). The observed up-regulation of Cort, Npy, Pnoc, and Adcyap1 mRNAs is therefore generally in line with the previously reported decrease in cortical excitability following long-term enrichment (Polley et al. 2004). Furthermore, mRNAs of the neuropeptide Cart and the regulatory enzyme $P d e 7 a$, both highly expressed in cortical layer 4 of the barrel cortex (Couceyro et al. 1997; Miro et al. 2001), were also up-regulated, but their role in modulating cortical signaling remains to be established. Interestingly, the up-regulated gene Lox may be related to (neuro)peptide signaling (Vora et al. 2010) and has been implicated in Purkinje cell dendritic development
(Li et al. 2010), while the present study suggests its involvement in cortical network reorganization. Finally, besides neuropeptide-related genes, VGlut2 (also named Slc17a6) was up-regulated as well, in line with previous observations showing that the expression of vesicular glutamate transporters is regulated by experience (Erickson et al. 2006), and therefore may affect glutamate signaling in cortical networks. In this regard, VGlut2 up-regulation has been linked to feedforward inhibition in cultured cortical neurons, where increased VGlut2 mRNA and protein levels have been described at excitatory synapses onto inhibitory interneurons after prolonged increases in glutamatergic synaptic activity induced by $\mathrm{GABA}_{\mathrm{A}}$ receptor activity blockade (Doyle et al. 2010). This is very much in line with our findings that VGlut2 mRNA is up-regulated after a long period of EE (increased sensory activity) and suggests, together with the involvement of neuropeptide signaling, its contribution to the reduced neuronal excitability found after a long period of sensory stimulation.

Interestingly, modulation of inhibition is a critical factor in regulating plasticity in other forms of long-term adult plasticity (Rosier et al. 1995; Arckens et al. 2000; Mitchell et al. 2007) as well as during development (Yuste and Sur 1999). Along the same lines, a large number of studies have demonstrated the role of neuropeptide signaling in learning and memory. For instance, Crh has been implicated in cognitive functional impairment after stress (Chen et al. 2010), while Cort impairs long-term memory, likely through inhibition of glutamatergic neurotransmission (de Lecea 2008). In contrast, both positive and negative effects of Npy on learning and memory have been reported (Flood et al. 1987; Thorsell et al. 2000). The effects of nociceptin, also known

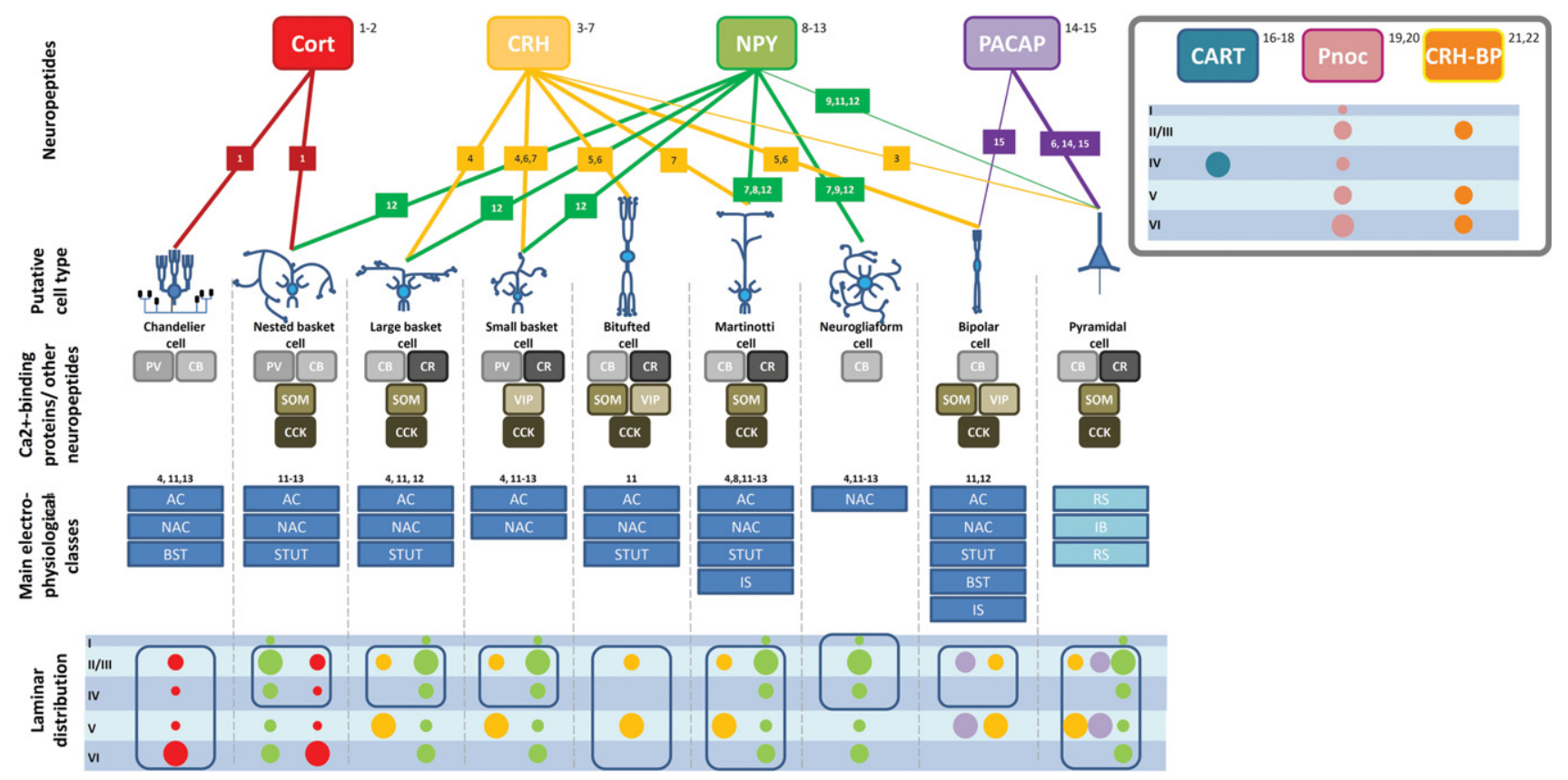

Figure 3. Scheme summarizing the laminar distribution and the main molecular, anatomical, and electrophysiological properties of the various neuronal types in which the EE-up-regulated neuropeptides are expressed. On top are the differentially regulated neuropeptides. The lines indicate in which cell type the peptides can be found: (thick line) common, (thin line) rare. Next, calcium-binding proteins ([PV] parvalbumin, [CB] calbindin, [CR] calretinin) and other neuropeptides which can be co-expressed with the EE-regulated neuropeptides are indicated, followed by the main electrophysiological classes corresponding to the putative cell type ([AC] accommodating, [NAC] nonaccommodating, [BST] bursting [STUT] stuttering, [IS] irregular spiking, $[\mathrm{RS}]$ regular spiking, [IB] intrinsic burst spiking). Finally, the colored circles indicate in which cortical layer the corresponding neuropeptide is expressed (laminar distribution), the size of the circles being proportional to the amount of expression; a blue rectangle defines the layers where the putative cell type can be found. There is insufficient information on putative cell type, electrophysiological classes, and additional molecular markers for the neuropeptides/neuropeptide-binding protein Cart, Pnoc and Crhbp. The information has been summarized on the basis of several studies; each study where the specific information has been derived from is indicated by a number, and the list of numbers with corresponding references, details of the study, and hyperlinks can be found in Supplemental Table 2. 
as orphanin FQ (N/OFQ), have been extensively investigated, and reported effects include memory impairments (Goeldner et al. 2008) and suppression of LTP (Bongsebandhu-phubhakdi and Manabe 2007). Adcyap1, or Pacap, has been shown to facilitate learning (Telegdy and Kokavszky 2000), and Pacap mutants display impaired hippocampal LTP (Matsuyama et al. 2003). Finally, Cart promotes spatial learning and memory in rats (Upadhya et al. 2011). Although the ensemble of these observations is in line with our findings, and further supports that neuropeptides have a crucial role in modulating neuronal function, direct demonstrations of enhanced neuronal specificity (in tuning or RF profile) during up-regulation of specific neuropeptides are currently lacking.

Bain-derived neurotrophic factor $(B d n f)$ mRNA is up-regulated in the somatosensory cortex after 2, 7, and $28 \mathrm{~d}$ of EE rearing in a "naturalistic habitat" (Gomez-Pinilla et al. 2011). Although we also found that $B d n f$ mRNA is up-regulated in the barrel cortex already after 30 min of EE (Vallès et al. 2011), in the present study we did not observe up-regulation of $B d n f$ mRNA after a long period of EE ( $28 \mathrm{~d})$. This could be due to differences in experimental design, such as the use of a "naturalistic habitat" instead of traditional EE rearing, timing of the sampling, or differences between rat strains studied (i.e., Sprague-Dawley vs. Long-Evans). In view of the long EE-period, we may have observed the downstream effects of earlier $B d n f$ up-regulation, because $B d n f$ induces the expression of two neuropeptide mRNAs (Npy and Pnoc) (Barnea et al. 2004; Ring et al. 2006) that were up-regulated in our study.

The up-regulation of neuropeptide signaling was accompanied by a striking down-regulation of a number of IEGs, classically seen as markers of neuronal activation and neuronal plasticity (Loebrich and Nedivi 2009). The down-regulated IEGs included Arc, Egr1 (Zif-268), Fos, Ier5, and Rnf39 (also named Lirf). This observation is another feature in our data that agrees well with the reduced cortical excitability following prolonged periods of sensory stimulation (Polley et al. 2004). These changes in neuronal excitability may increase signal-tonoise ratio and improve information processing in cortical networks. Besides IEGs, other genes were also down-regulated; the interpretation of these findings can be found in the Supplemental Discussion.

Strikingly, we observed a small number of regulated genes in the present study, whereas we previously found many differentially expressed genes following a short period of EE (Vallès et al. 2011). This suggests that during the initial phases of plasticity (i.e., after short-term EE) a complex set of molecular cascades is activated, while the long-term EE changes observed in the present study reflect the stable steady-state molecular signature resulting from the plastic reorganization of the circuitry. The molecular effects observed after short-term and long-term EE exposure could be analogous to those underlying the "acquisition" phase (early learning) and the "asymptotic phase" in skill learning, respectively, in which the latter phase results in long-term memory traces that can include sensory and/or motor cortex (Karni and Bertini 1997; Schoups et al. 2001). In addition, the molecular changes that we describe here are in line with the previously reported morphological and functional changes after long-term sensory experience (Polley et al. 2004). Without excluding the contributions of higher-level areas to implicit memory formation (Law and Gold 2008; Xiao et al. 2008; Reed et al. 2011), our data support the idea that low-level sensory cortical areas can contribute to the long-term maintenance of memory traces acquired during stimulus exposure and skill learning (Karni and Bertini 1997; Schoups et al. 2001). Along these lines, we suggest that after learning or experience, increased inhibitory function may be an integral part of the manner in which memory traces are maintained in cortical networks (Tremere et al. 2003).

\section{Acknowledgments}

We thank Arjen J. Boender, Mahshid Gazorpak, and Rachel Guest for valuable technical assistance. This research was supported by VICI grant 453_04_002 from the Netherlands Foundation of Scientific Research (NWO) to P.D.W.

\section{References}

Arckens L, Schweigart G, Qu Y, Wouters G, Pow DV, Vandesande F, Eysel UT, Orban GA. 2000. Cooperative changes in GABA, glutamate and activity levels: The missing link in cortical plasticity. Eur J Neurosci 12: $4222-4232$.

Bacci A, Huguenard JR, Prince DA. 2002. Differential modulation of synaptic transmission by neuropeptide $\mathrm{Y}$ in rat neocortical neurons. Proc Natl Acad Sci 99: 17125-17130.

Barnea A, Roberts J, Croll SD. 2004. Continuous exposure to brain-derived neurotrophic factor is required for persistent activation of TrkB receptor, the ERK signaling pathway, and the induction of neuropeptide Y production in cortical cultures. Brain Res 1020: $106-117$.

Barnes SJ, Finnerty GT. 2010. Sensory experience and cortical rewiring. Neuroscientist 16: 186-198.

Bongsebandhu-phubhakdi S, Manabe T. 2007. The neuropeptide nociceptin is a synaptically released endogenous inhibitor of hippocampal long-term potentiation. J Neurosci 27: 4850-4858.

Chen Y, Rex CS, Rice CJ, Dube CM, Gall CM, Lynch G, Baram TZ. 2010. Correlated memory defects and hippocampal dendritic spine loss after acute stress involve corticotropin-releasing hormone signaling. Proc Natl Acad Sci 107: 13123-13128.

Couceyro PR, Koylu EO, Kuhar MJ. 1997. Further studies on the anatomical distribution of CART by in situ hybridization. J Chem Neuroanat 12: $229-241$.

de Lecea L. 2008. Cortistatin-functions in the central nervous system. Mol Cell Endocrinol 286: 88-95.

de Lecea L, del Rio JA, Criado JR, Alcantara S, Morales M, Danielson PE, Henriksen SJ, Soriano E, Sutcliffe JG. 1997. Cortistatin is expressed in a distinct subset of cortical interneurons. J Neurosci 17: 5868-5880.

Doyle S, Pyndiah S, De Gois S, Erickson JD. 2010. Excitation-transcription coupling via calcium/calmodulin-dependent protein kinase/ERK1/2 signaling mediates the coordinate induction of VGLUT2 and Narp triggered by a prolonged increase in glutamatergic synaptic activity. $J$ Biol Chem 285: 14366-14376.

Erickson JD, De Gois S, Varoqui H, Schafer MK, Weihe E. 2006. Activity-dependent regulation of vesicular glutamate and GABA transporters: A means to scale quantal size. Neurochem Int 48: 643-649.

Feldman DE, Brecht M. 2005. Map plasticity in somatosensory cortex. Science 310: $810-815$.

Flood JF, Hernandez EN, Morley JE. 1987. Modulation of memory processing by neuropeptide Y. Brain Res 421: 280-290.

Fox K, Wong ROL. 2005. A comparison of experience-dependent plasticity in the visual and somatosensory systems. Neuron 48: 465-477.

Fries P. 2005. A mechanism for cognitive dynamics: Neuronal communication through neuronal coherence. Trends Cogn Sci 9: 474-480.

Froc DJ, Christie BR. 2005. Corticotrophin-releasing hormone decreases synaptic transmission in rat sensorimotor cortex in vivo. Neuroscience 134: $965-973$.

Frostig RD. 2006. Functional organization and plasticity in the adult rat barrel cortex: Moving out-of-the-box. Curr Opin Neurobiol 16: 445-450.

Gallopin T, Geoffroy H, Rossier J, Lambolez B. 2006. Cortical sources of CRF, NKB, and CCK and their effects on pyramidal cells in the neocortex. Cereb Cortex 16: 1440-1452.

Goeldner C, Reiss D, Wichmann J, Meziane H, Kieffer BL, Ouagazzal AM. 2008. Nociceptin receptor impairs recognition memory via interaction with NMDA receptor-dependent mitogen-activated protein kinase/ extracellular signal-regulated kinase signaling in the hippocampus. $J$ Neurosci 28: 2190-2198.

Gomez-Pinilla F, Ying Z, Agoncillo T, Frostig R. 2011. The influence of naturalistic experience on plasticity markers in somatosensory cortex and hippocampus: Effects of whisker use. Brain Res 1388: 39-47.

Hannibal J. 2002. Pituitary adenylate cyclase-activating peptide in the rat central nervous system: An immunohistochemical and in situ hybridization study. J Comp Neurol 453: 389-417.

Hu E, Demmou L, Cauli B, Gallopin T, Geoffroy H, Harris-Warrick RM, Paupardin-Tritsch D, Lambolez B, Vincent P, Hepp R. 2011. VIP, CRF, and PACAP act at distinct receptors to elicit different cAMP/PKA dynamics in the neocortex. Cereb Cortex 21: 708-718.

Karagiannis A, Gallopin T, David C, Battaglia D, Geoffroy H, Rossier J, Hillman EM, Staiger JF, Cauli B. 2009. Classification of NPY-expressing neocortical interneurons. J Neurosci 29: 3642-3659. 
Karni A, Bertini G. 1997. Learning perceptual skills: Behavioral probes into adult cortical plasticity. Curr Opin Neurobiol 7: 530-535.

Knott GW, Quairiaux C, Genoud C, Welker E. 2002. Formation of dendritic spines with GABAergic synapses induced by whisker stimulation in adult mice. Neuron 34: $265-273$.

Kuzmin A, Madjid N, Johansson B, Terenius L, Ogren SO. 2009. The nociceptin system and hippocampal cognition in mice: A pharmacological and genetic analysis. Brain Res 1305: Suppl: S7-S19.

Law CT, Gold JI. 2008. Neural correlates of perceptual learning in a sensorymotor, but not a sensory, cortical area. Nat Neurosci 11: 505-513.

Li J, Gu X, Ma Y, Calicchio ML, Kong D, Teng YD, Yu L, Crain AM, Vartanian TK, Pasqualini R, et al. 2010. Nna1 mediates Purkinje cell dendritic development via lysyl oxidase propeptide and NF-кB signaling. Neuron 68: 45-60.

Loebrich S, Nedivi E. 2009. The function of activity-regulated genes in the nervous system. Physiol Rev 89: 1079-1103.

Markram H, Toledo-Rodriguez M, Wang Y, Gupta A, Silberberg G, Wu C. 2004. Interneurons of the neocortical inhibitory system. Nat Rev Neurosci 5: 793-807.

Matsuyama S, Matsumoto A, Hashimoto H, Shintani N, Baba A. 2003. Impaired long-term potentiation in vivo in the dentate gyrus of pituitary adenylate cyclase-activating polypeptide (PACAP) or PACAP type 1 receptor-mutant mice. Neuroreport 14: 2095-2098.

Miro X, Perez-Torres S, Palacios JM, Puigdomenech P, Mengod G. 2001. Differential distribution of cAMP-specific phosphodiesterase 7A mRNA in rat brain and peripheral organs. Synapse 40: 201-214.

Mitchell JF, Sundberg KA, Reynolds JH. 2007. Differential attention-dependent response modulation across cell classes in macaque visual area V4. Neuron 55: 131-141.

Polley DB, Chen-Bee CH, Frostig RD. 1999. Two directions of plasticity in the sensory-deprived adult cortex. Neuron 24: 623-637.

Polley DB, Kvasnak E, Frostig RD. 2004. Naturalistic experience transforms sensory maps in the adult cortex of caged animals. Nature 429: 67-71.

Reed A, Riley J, Carraway R, Carrasco A, Perez C, Jakkamsetti V, Kilgard MP. 2011. Cortical map plasticity improves learning but is not necessary for improved performance. Neuron 70: 121-131.

Ring RH, Alder J, Fennell M, Kouranova E, Black IB, Thakker-Varia S. 2006. Transcriptional profiling of brain-derived-neurotrophic factor-induced neuronal plasticity: A novel role for nociceptin in hippocampal neurite outgrowth. J Neurobiol 66: 361-377.

Roberto M, Scuri R, Brunelli M. 2001. Differential effects of PACAP-38 on synaptic responses in rat hippocampal CA1 region. Learn Mem 8: $265-271$.

Rosier AM, Arckens L, Demeulemeester H, Orban GA, Eysel UT, Wu YJ, Vandesande F. 1995. Effect of sensory deafferentation on immunoreactivity of GABAergic cells and on GABA receptors in the adult cat visual cortex. J Comp Neurol 359: 476-489.

Schoups A, Vogels R, Qian N, Orban G. 2001. Practising orientation identification improves orientation coding in V1 neurons. Nature 412: $549-553$.
Sillito AM. 1975. The contribution of inhibitory mechanisms to the receptive field properties of neurones in the striate cortex of the cat. $J$ Physiol 250: 305-329.

Spier AD, De Lecea L. 2000. Cortistatin: A member of the somatostatin neuropeptide family with distinct physiological functions. Brain Res Rev 33: 228-241.

Telegdy G, Kokavszky K. 2000. The action of pituitary adenylate cyclase activating polypeptide (PACAP) on passive avoidance learning. The role of transmitters. Brain Res 874: 194-199.

Thorsell A, Michalkiewicz M, Dumont Y, Quirion R, Caberlotto L, Rimondini R, Mathe AA, Heilig M. 2000. Behavioral insensitivity to restraint stress, absent fear suppression of behavior and impaired spatial learning in transgenic rats with hippocampal neuropeptide $\mathrm{Y}$ overexpression. Proc Natl Acad Sci 97: 12852-12857.

Tremere L, Pinaud R, De Weerd P. 2003. Contributions of inhibitory mechanisms to perceptual completion and cortical reorganization. In Filling-in: from perceptual completion to cortical reorganization (ed. Pessoa L, De Weerd P), Vol. 1, pp. 295-322. Oxford University Press, Oxford.

Upadhya MA, Nakhate KT, Kokare DM, Singru PS, Subhedar NK. 2011. Cocaine- and amphetamine-regulated transcript peptide increases spatial learning and memory in rats. Life Sci 88: 322-334.

Vallès A, Boender AJ, Gijsbers S, Haast RA, Martens GJ, de Weerd P. 2011. Genomewide analysis of rat barrel cortex reveals time- and layer-specific mRNA expression changes related to experience-dependent plasticity. J Neurosci 31: 6140-6158.

Vora SR, Guo Y, Stephens DN, Salih E, Vu ED, Kirsch KH, Sonenshein GE, Trackman PC. 2010. Characterization of recombinant lysyl oxidase propeptide. Biochemistry 49: 2962-2972.

Welker E, Rao SB, Dorfl J, Melzer P, van der Loos H. 1992. Plasticity in the barrel cortex of the adult mouse: Effects of chronic stimulation upon deoxyglucose uptake in the behaving animal. J Neurosci 12: $153-170$.

Xiao LQ, Zhang JY, Wang R, Klein SA, Levi DM, Yu C. 2008. Complete transfer of perceptual learning across retinal locations enabled by double training. Curr Biol 18: 1922-1926.

Yan XX, Baram TZ, Gerth A, Schultz L, Ribak CE. 1998a. Co-localization of corticotropin-releasing hormone with glutamate decarboxylase and calcium-binding proteins in infant rat neocortical interneurons. Exp Brain Res 123: 334-340.

Yan XX, Toth Z, Schultz L, Ribak CE, Baram TZ. 1998b. Corticotropin-releasing hormone (CRH)-containing neurons in the immature rat hippocampal formation: Light and electron microscopic features and colocalization with glutamate decarboxylase and parvalbumin. Hippocampus 8: 231-243.

Yuste R, Sur M. 1999. Development and plasticity of the cerebral cortex: From molecules to maps. J Neurobiol 41: 1-6.

Received February 14, 2014; accepted in revised form March 14, 2014. 


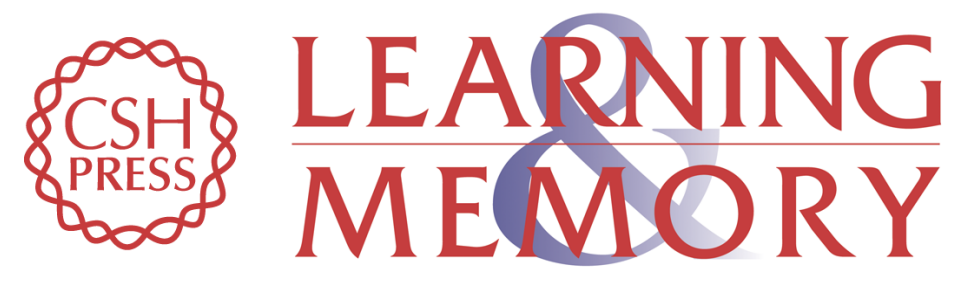

\section{Molecular correlates of cortical network modulation by long-term sensory experience in the adult rat barrel cortex}

Astrid Vallès, Ivica Granic, Peter De Weerd, et al.

Learn. Mem. 2014, 21:

Access the most recent version at doi:10.1101/lm.034827.114

\section{Supplemental http://learnmem.cshlp.org/content/suppl/2014/04/28/21.6.305.DC1 Material}

References This article cites 53 articles, 12 of which can be accessed free at: http://learnmem.cshlp.org/content/21/6/305.full.html\#ref-list-1

Creative This article is distributed exclusively by Cold Spring Harbor Laboratory Press for the Commons first 12 months after the full-issue publication date (see

License http://learnmem.cshlp.org/site/misc/terms.xhtml). After 12 months, it is available under a Creative Commons License (Attribution-NonCommercial 4.0 International), as described at http://creativecommons.org/licenses/by-nc/4.0/.

Email Alerting Receive free email alerts when new articles cite this article - sign up in the box at the Service top right corner of the article or click here. 